\title{
Two new species of the beetle genus Pogonoglossus from the Pilbara region of north-western Australia (Coleoptera: Carabidae: Physocrotaphini)
}

\author{
Martin Baehr \\ Zoologische Staatssammlung, Münchhausenstr. 21, D-81247 München, Germany. \\ Email: martin.baehr@zsm.mwn.de
}

\begin{abstract}
Two new species of the carabid genus Pogonoglossus Chaudoir are described from the Pilbara region of north-western Australia: $P$. frater sp. nov. and $P$. soror sp. nov. The new species were detected in the course of a survey for subterranean organisms in mining areas and were collected by scraping the inside of drill holes in the ground. Both new species are poorly pigmented, possess rather small eyes and very elongate antennae, character states which are typically associated with subterranean or cavicolous habits. Both species, although quite differently shaped, seem to be nearest related to P. rufopiceus Baehr, recorded from a cave in the northern part of the Northern Territory. These species are included in a revised key to the Australian species of the genus Pogonoglossus.
\end{abstract}

KEYWORDS: taxonomy, morphology, Western Australia, cavicolous

\section{INTRODUCTION}

Physocrotaphini (formerly also called Helluodini) is a small tribe of characteristically shaped carabid beetles that occurs with c. 40 described species in the Oriental and Papuan-Australian Regions (Lorenz 2005). The affinities of the tribe are still uncertain (Moore 1998), but it may be more closely related to the mainly Afrotropical Anthiini than to any other tribe. The Oriental species of the most diverse genus Pogonoglossus urgently require revision, because species identification without comparison with types is presently barely possible, and, in addition, because several additional species are believed to exist. The species from New Guinea were worked on by Darlington (1968) in his monumental monograph on the New Guinean Carabidae, and the Australian species were revised by Baehr (1988). Since that time, however, a few additional species have been described from both New Guinea and Australia (Baehr 1993, 1995, 2005, 2008).

Only the genus Pogonoglossus is recorded from Australia but specimens are rarely collected. Therefore almost nothing is known about the habits and life histories of any Australian species. Of the presently described species, the five pigmented ones have been most commonly collected at light in open eucalyptus forest, tropical savannah, and 'dry rain forest'. One specimen was recorded as being sampled from under bark of a log. The single described rufous species, P. rufopiceus Baehr, 1993, was collected in a cave.

Thanks to the courtesy of Nadine Guthrie, Brian Hanich and Nikolai Tatarnic (Perth) I received a small sample of carabid beetles from different tribes for identification that were collected during a survey in some mining areas in the Pilbara, north-western Western Australia. All specimens were sampled by 'trog scrape' which means that troglobiotic animals were collected from drill bores in the ground in iron ore mining areas as described by Halse and Pearson (2014) and as noted below. As a consequence, the sample consists of more or less depigmented specimens with small eyes or even without visible eyes. Included in the sample are specimens from the tribes Physocrotaphini, Zuphiini, and Bembidiini, subtribe Anillina. Both Zuphiini and Anillina are known to have several soil or cave inhabiting species. Known members of the tribe Physocrotaphini are often regarded as forest inhabiting beetles, however, in Australia one species has been recorded from a cave

In this paper two new species of the tribe Physocrotaphini are described. 


\section{METHODS}

In the taxonomic survey standard methods are used. The genitalia were removed from specimens relaxed for a night in a jar under moist atmosphere, then cleaned for a short while in hot $10 \% \mathrm{KOH}$. Specimens are very fragile because they are preserved in $100 \%$ ethanol, so instead of photographs the habitus of head and pronotum is depicted in drawings.

Measurements were taken using a stereo microscope with an ocular micrometer. Length has been measured from apex of labrum to apex of elytra. Length of pronotum was measured in a straight line from the apex of the anterior angles to the most produced part of the base. Length of the elytra was measured from the most advanced part of the humerus to the very apex.

The holotypes of the new species are stored in Western Australian Museum, Perth (WAM).

\section{COLLECTING METHOD}

Halse and Pearson (2014) describe extensively a method of sampling subterranean, but not cavicolous, arthropods living in the earth, during a survey carried out in iron ore mining areas in the Pilbara, northwestern Australia. The collectors used nets which were lowered into drill bores in the ground and then pulled out again. During the lifting of the net from the hole, the margins of the bores were scraped by the net and animals that fell inside were brought to the surface. For the carabid species worked on in the present paper, this was done in depths of up to $43 \mathrm{~m}$ below surface level. According to the authors this collecting method in general was more successful than the method of sampling animals in the drill bores by pitfall traps.

\section{TAXONOMY}

\section{Family Carabidae Latreille, 1802}

\section{Subfamily Harpalinae Bonelli, 1810}

Tribe Physocrotaphini Chaudoir, 1862

\section{Genus Pogonoglossus Chaudoir, 1862}

Pogonoglossus Chaudoir, 1862: 304.

\section{TYPE SPECIES}

Pogonoglossus validicornis Chaudoir, 1862, by monotypy.

\section{REMARKS}

Pogonoglossus is the commonest genus of Physocrotaphini and is covers by far the largest number of species. All species are markedly depressed and rather elongate, possess a large head with elongate mandibles, a wide, cordiform prothorax, and parallel-sided elytra.

Most Australian species occur in north-eastern Queensland, only P. porosus Sloane has been also recorded from the northernmost parts of Northern Territory and Western Australia, and the cave inhabiting
P. rufopiceus Baehr is only known from the vicinity of Katherine, Northern Territory. The two new species enlarge the range of the genus in Australia to the Pilbara Region.

\section{Pogonoglossus frater sp. nov.}

Figures 1, 3

http://www.zoobank.org/urn:Isid:zoobank. org:act:1C95C5B5-734E-4F51-9B73-9FE898DC9DA8

\section{MATERIAL EXAMINED}

\section{Holotype}

Australia: Western Australia: ,'W.A.: Mining Area C, c. $96 \mathrm{~km}$ WNW. Newman 22 54'33.50"S $118^{\circ} 56^{\prime} 36.80^{\prime \prime} \mathrm{E}$ (WGS 84) 24 June 2010 M.K. Curran, G.B. Pearson (PSC0165R) Trog scrape' (WAM E88466).

\section{DIAGNOSIS}

With its pale colouration, relatively small eyes and elongate antenna, this species is quite similar to $P$. soror sp. nov. and P. rufopiceus. It is distinguished from $P$. soror by its larger body size, wider prothorax, and shorter elytra, and from P. rufopiceus by smaller eyes, wider pronotum with narrower base, shorter elytra, and longer antenna.

\section{DESCRIPTION}

Measurements: Length: $8.3 \mathrm{~mm}$; width: $2.95 \mathrm{~mm}$. Ratio width of base/width of apex of pronotum: 1.13; ratio width/length of pronotum: 1.26; ratio width of pronotum/width of elytra: 0.72 ; ratio length/width of elytra: 1.64; ratio length/width of $10^{\text {th }}$ antennomere: 3.2 .

Colour: Head and pronotum reddish. Elytra reddishpiceous, the lateral margin narrowly pale red. apical margin of clypeus, labrum, and mandibles piceous. Femora dirty yellow, undersurface of tibiae and tarsi reddish-piceous. Lower surface pale red, head and pronotum, and apical part of abdomen slightly darker.

Head (Figure 1): Slightly narrower than pronotum, wide between eyes. Eye comparatively small, shorter than orbit, laterad but moderately protruded. Frons with a shallow, semicircular, median impression behind clypeal suture, neck separated by a deep, convex furrow. At posterior border of eye a small boss. Behind and slightly below this boss a fairly deep suture, below that with a protuberance that bears c. 3 elongate setae at tip. This protuberance is projected laterad almost as far as eye, the suborbital curvature very convex, longer than eye. Mandibles fairly elongate, inner border almost straight, incurved near apex. Palpi moderately elongate, slightly widened apicad, sparsely setose. Lateral parts of mentum laterad triangularly protruded, with two elongate setae. Antenna very elongate, scapus elongate, about as long as width of base of clypeus, $5^{\text {th }}$ to $7^{\text {th }}$ antennomeres $>3 \mathrm{x}$ as long as wide. Surface of head sparsely, though rather coarsely punctate and pilose, pilosity very short and inclined anteriad. Microreticulation absent, surface very glossy. 
Prothorax (Figure 1): Large and rather wide, much wider than long, markedly cordiform, widest at apical third. Apex wide, slightly concave, anterior angles produced, at tip slightly obtuse. Lateral margins regularly convex, in basal fourth straight and parallel-sided. Basal angles slightly more than rectangular, near tip slightly concave, the very tip being a very small denticle. Base comparatively narrow, in middle straight, laterally slightly oblique. Lateral margin slightly raised, marginal explanation wide. Apex indistinctly margined, base not margined. Disk gently convex. Median line fine, slightly impressed, neither attaining apex nor base. Both transverse sulci very shallow. Basal grooves shallow, wide. Lateral margin without a visible lateral seta, but at least the puncture of the basal seta visible. Surface with moderately dense, fairly coarse, but shallow punctures, and with dense, short, slightly declined pilosity. Microreticulation extremely fine and superficial, composed of more or less isodiametric meshes.

Elytra: Elongate and parallel-sided, but comparatively short (in genus); dorsal surface depressed. Humerus little projected, rounded. Lateral margins straight. Apex slightly concave and slightly oblique; external apical angle widely rounded. Striae complete and well impressed, intervals raised, fairly densely punctate in 2-3 rows, punctures slightly rasp-shaped. Pilosity fairly dense, depressed. Microreticulation distinct, slightly transverse. Marginal setae very elongate. Metathoracic wings apparently complete.

Lower surface: Densely punctate and pubescent. Metepisternum elongate, c. $2 \mathrm{x}$ as long as wide at apex. Terminal sternite in male on either side with one seta in middle (but setae broken) and with 3 setae near apical border.

Legs: Elongate. All tibiae very densely setose with longer and shorter hairs. Also tarsi pilose on upper and lower surfaces. Three basal tarsomeres of the male protarsus little widened, sparsely, biseriately pilose.

Male genitalia (Figure 3): Genital ring wide, triangular but slightly convex, slightly asymmetric, with very wide base. Aedagus short and compact, slightly asymmetric; lower surface straight. Apex short and wide, asymmetrically, obtusely triangularconvex. Orificium elongate, dorsally on either side with a sclerotised rod. Internal sac with several folds and with two complexly twisted, narrow, sclerotised pieces. Parameres very dissimilar, left paramere large, compact, right paramere narrow, with elongate, hooked peduncle, both asetose at apex.

Female gonocoxites: Unknown.

Variation: Unknown.

\section{DISTRIBUTION}

This species is known only from the type locality north-west of Newman in the Pilbara region of northwestern Western Australia.

\section{REMARKS}

The holotype was sampled by 'trog scrape' as discussed above under 'Collecting method', but the depth of the bore was not stated.
This species is probably closely related to $P$. soror and P. rufopiceus. However, as the male genitalia of both of these species are yet unknown, and because all three species are depigmented because of their habits as cavicolous or soil-inhabiting species, any similarities might simply be due to homoplasy.

\section{ETYMOLOGY}

The name means 'brother' and refers to the fact that the holotype is a male.

\section{Pogonoglossus soror sp. nov.}

Figures 2, 4

http://www.zoobank.org/urn:Isid:zoobank. org:act:6C76DFAE-742F-49EA-89CD-FEC276F0958F

\section{MATERIAL EXAMINED}

\section{Holotype}

Australia: Western Australia: ,W.A.: Kutayi, c. $71 \mathrm{~km}$ S. Nullagine $22^{\circ} 31^{\prime} 24.4^{\prime \prime S} 120^{\circ} 01^{\prime} 59.2^{\prime \prime} \mathrm{E}$ (WGS 84) 27 August 2013 J.S. Cocking, J.W. Quartermaine (BH0034) Trog scrape, 43 m' (WAM E88467).

\section{DIAGNOSIS}

With its pale colouration, small eyes, and elongate antenna this species is quite similar to $P$. frater and $P$. rufopiceus. It is distinguished from $P$. frater by its smaller body size, narrower prothorax, and longer elytra, and from $P$. rufopiceus by its smaller eye, narrower pronotum, slightly longer elytra, and longer antenna.

\section{DESCRIPTION}

Measurements: Length: $6.3 \mathrm{~mm}$; width: $2.1 \mathrm{~mm}$. Ratio width of base/width of apex of pronotum: 1.22; ratio width/length of pronotum: 1.15; ratio width of pronotum/ width of elytra: 0.65 ; ratio length/width of elytra: 1.76 ; ratio length/width of $10^{\text {th }}$ antennomere: 3.2 .

Colour: Head and pronotum pale reddish, elytra very slightly darker, the lateral margin narrowly dirty yellow. Legs yellow, tibiae and tarsi barely darker. Lower surface pale red.

Head (Figure 2): As wide as pronotum, wide between eyes. Eye comparatively small, shorter than orbit, laterad rather protruded. Frons with a shallow, about quadrate, median impression behind clypeal suture, neck separated by a deep, curved furrow. At posterior border of eye a small boss. Behind and slightly below this boss a shallow suture, below that with a very small protuberance that bears c. 3 elongate setae at tip. This protuberance is far less projected laterad than eye, the suborbital curvature very convex, longer than eye. Mandibles comparatively short, inner border almost straight, only incurved near apex. Palpi moderately elongate, slightly widened apicad, sparsely setose. Lateral parts of mentum laterad triangularly protruded, 
with two elongate setae. Antenna very elongate, scapus elongate, about as long as width of base of clypeus, $5^{\text {th }}$ to $7^{\text {th }}$ antennomeres $>3 \mathrm{x}$ as long as wide. Surface of head sparsely but rather coarsely punctate and pilose, pilosity very short and inclined anteriad. Microreticulation absent, surface very glossy.

Prothorax (Figure 2): Rather narrow, slightly wider than long, markedly cordiform, widest at apical fourth. Apex wide, almost straight, anterior angles little produced, rounded. Lateral margins in apical three fifths regularly convex, in basal two fifths straight and parallel-sided. Basal angles almost rectangular, near tip extremely slightly concave, the very tip being a small but distinct denticle. Base comparatively wide, in middle straight, laterally fairly oblique. Lateral margin slightly raised, marginal explanation moderately wide. Both apex and base not margined. Disk gently convex. Median line distinct, slightly impressed, neither attaining apex nor base. Both transverse sulci very shallow. Basal grooves shallow, wide. Lateral margin without a visible lateral seta, but at least the puncture of the basal seta visible. Surface with moderately dense, coarse, but shallow punctures that are arranged in about transverse rows, with short, slightly declined pilosity. Microreticulation fine and superficial, composed of more or less isodiametric meshes.

Elytra: Elongate and parallel-sided, narrow; dorsal surface depressed. Humerus little projected, rounded. Lateral margins straight. Apex slightly concave and slightly oblique; external apical angles widely rounded. Striae complete and well impressed, intervals raised, fairly densely punctate in about two rows, punctures slightly rasp-shaped. Pilosity fairly dense, depressed. Microreticulation distinct, slightly transverse. Marginal setae very elongate. Metathoracic wings apparently complete.

Lower surface: Densely punctate and pubescent. Metepisternum elongate, slightly $>2 \mathrm{x}$ as long as wide at apex. Terminal sternite in female on either side with one elongate seta in middle and with 3-4 setae near apical border.

Legs: Elongate. All tibiae very densely setose with longer and shorter hairs. Also tarsi pilose on upper and lower surfaces. Vestiture of male protarsus unknown.

Male genitalia: Unknown.

Female gonocoxites (Figure 4): Gonocoxite 1 elongate, with 3-4 short, ensiform seta at median apical rim. Gonocoxite 2 rather elongate, curved, with acute apex, with 2 small ensiform setae in the apical half of the ventro-lateral surface, one fairly elongate, strong nematiform seta in the basal half of the dorso-median surface, and a short nematiform seta at the apical fourth of the dorso-median surface that originates from a pit. Lateral plate sclerotised and at apical rim with c. 8 very elongate nematiform setae.

Variation: Unknown.

\section{DISTRIBUTION}

This species is known only from the type locality south of Nullagine in the Pilbara region of north-western Western Australia.

\section{REMARKS}

The holotype was sampled by 'trog scrape' as discussed above under 'Collecting method', at $43 \mathrm{~m}$ below surface.

For relationships see under $P$. frater.

\section{ETYMOLOGY}

The name means 'sister' and refers to the fact that the holotype is a female.

\section{Revised key to the Australian species of Pogonoglossus}

1. Orbit behind or below eye with a distinct tuberosity and/or a tooth; base of pronotum laterally perceptibly oblique.....

Orbit behind or below eye without tuberosity or tooth; base of pronotum laterally almost straight (NE. Queensland)......... P. inarmatus Baehr, 1988

2. Orbit behind eyes with a tooth or tuberosity ........... 3

Orbit below eyes with a tooth or tuberosity, separated by a furrow.

3. Orbital tooth tiny; intervals of elytra glossy, punctation uni- to biseriate (c. New South Wales). .P. danielsi Baehr, 2008

Orbital tooth large; intervals of elytra distinctly microreticulate, punctation three- to quadriseriate (E. Queensland)

4. Body size larger, $8.7-10.4 \mathrm{~mm}$; orbit markedly swollen, almost as long as eye, posteriorly gently curved, laterally projected beyond eye; lateral border of pronotum widely explanate; antenna elongate, terminal antennomeres $>2 \mathrm{x}$ as long as wide (E. Queensland).

P. inflaticeps (Sloane, 1904)

Body size smaller, 7.2-8.7 mm; orbit less swollen, c. half of length of eye, posteriorly almost transverse, laterally much less projected than eye; lateral border of pronotum narrow, not explanate; antenna short, terminal antennomeres c. $1.5 \mathrm{x}$ as long as wide (New Guinea; E. Queensland: Cape York Peninsula) ........ P. parvus Darlington, 1968

5. Colour dark piceous; eye larger, though laterally less projected, longer than orbit; suborbital tuberosity laterally much more projected; antenna shorter, scapus distinctly shorter than width of base of clypeus, terminal antennomeres $<2.25 \mathrm{x}$ as long as wide (E. Queensland; N. Northern Territory; N. Western Australia north of Great Sandy Desert) P. porosus (Sloane, 1904) 


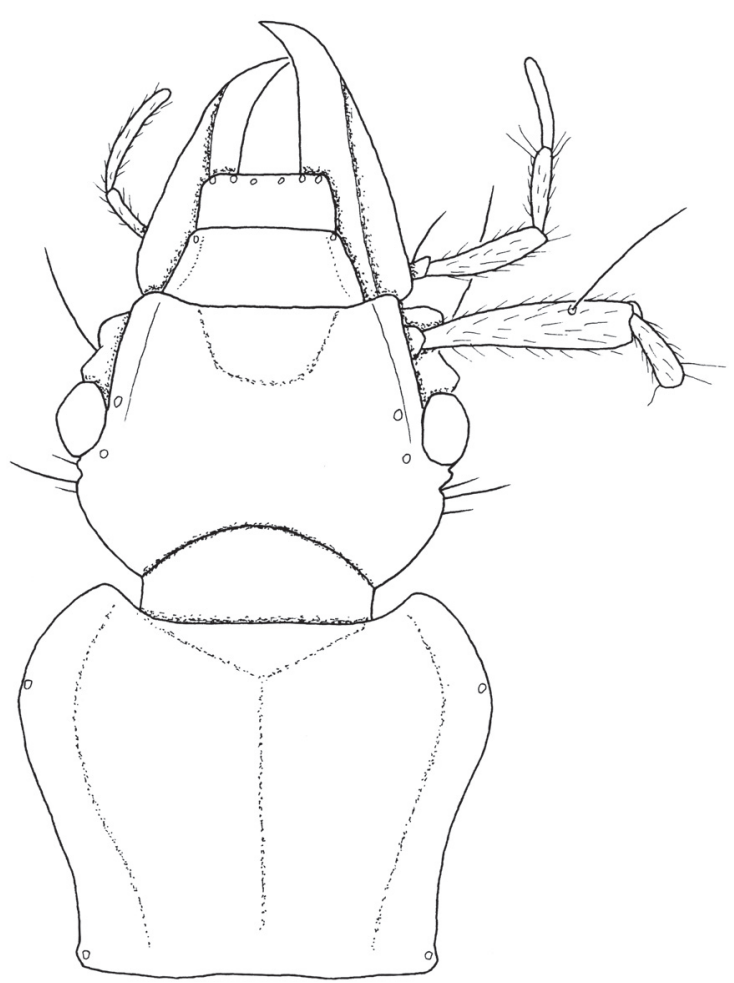

FIGURE 1 Head and pronotum of Pogonoglossus frater sp. nov. Scale bars $=1 \mathrm{~mm}$.

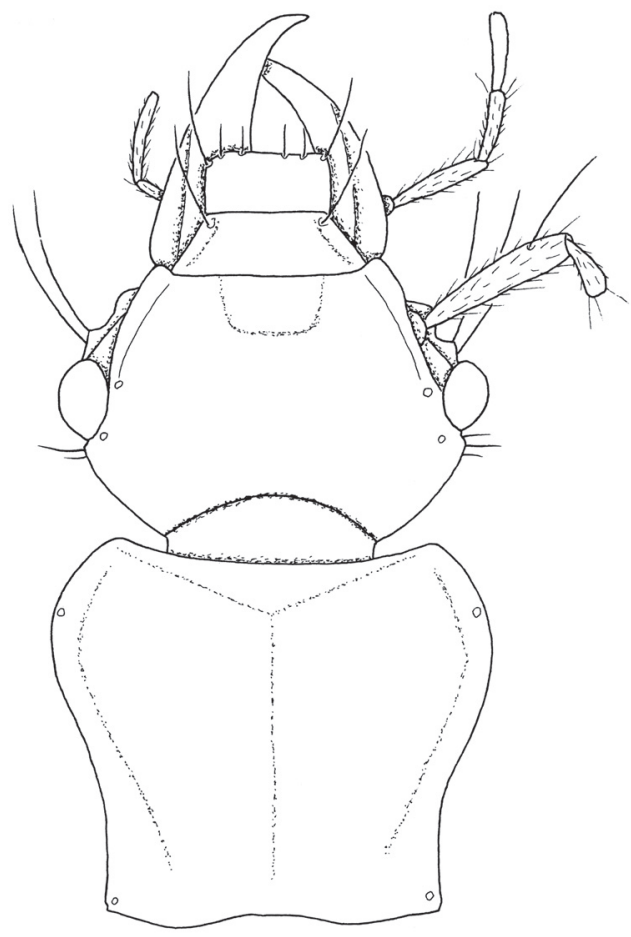

FIGURE 2 Head and pronotum of Pogonoglossus soror sp. nov. Scale bars $=1 \mathrm{~mm}$.
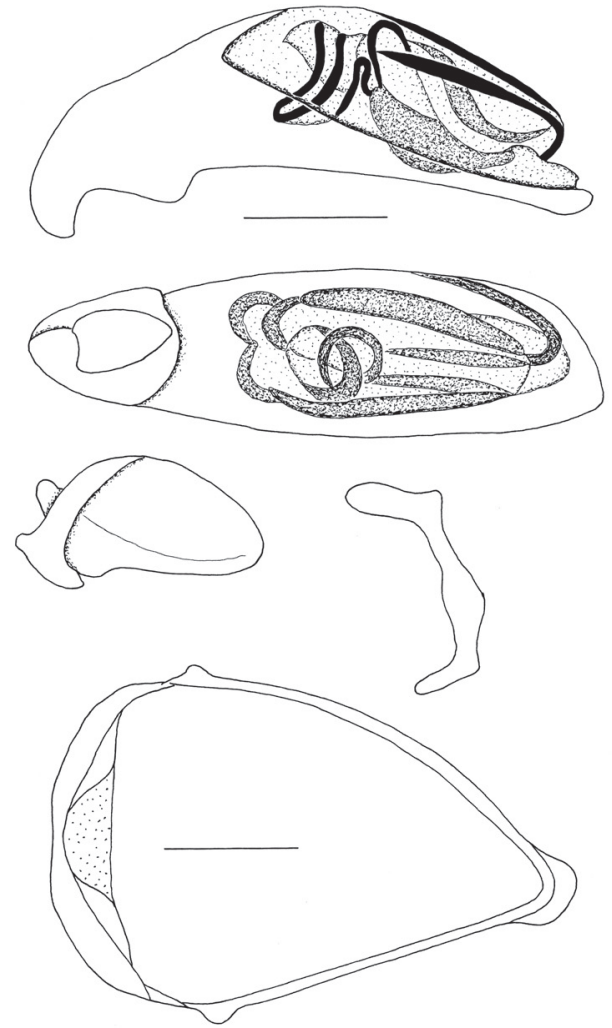

FIGURE 3 Pogonoglossus frater sp. nov., male aedeagus, left side and lower surface, parameres, genital ring.

Scale bars $=0.25 \mathrm{~mm}$.

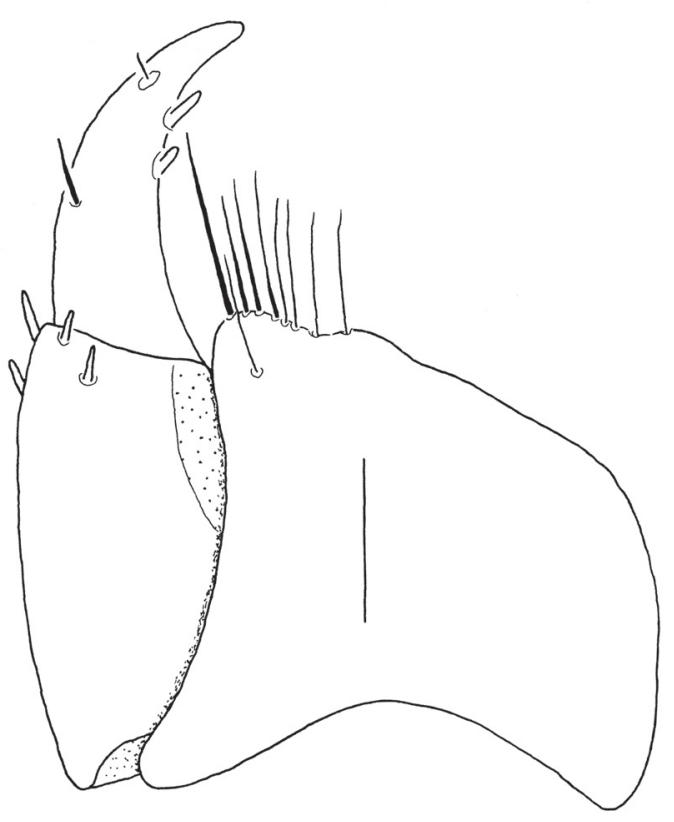

FIGURE 4 Pogonoglossus soror sp. nov., female gonocoxites and lateral plate. Scale bar $=0.1 \mathrm{~mm}$. 
Colour more or less pale red; eye smaller, as long as orbit, or shorter, though laterally more projected; suborbital tuberosity laterally much less projected; antenna longer, scapus almost as long as width of base of clypeus, or longer, terminal antennomeres $>2.5 \mathrm{x}$ as long as wide .. 6

6. Body size larger, $>8 \mathrm{~mm}$; pronotum wider, ratio width/length $>1.2$

Body size smaller, $<6.3 \mathrm{~mm}$; pronotum narrower, ratio width/length 1.15 (Figure 2) (NW. Western Australia: Pilbara). P. soror sp. nov.

7. Pronotum wider, with narrower base, ratio width/ length of pronotum 1.26, ratio base/apex 1.13; elytra shorter, ratio length/width 1.64; eye laterad less produced (Figure 1); antenna longer, terminal antennomeres $>3 \mathrm{x}$ as long as wide (NW. Western Australia: Pilbara). $P$. frater sp. nov.

Pronotum narrower, with wider base, ratio width/ length of pronotum 1.20, ratio base/apex 1.24; elytra longer, ratio length/width 1.73; antenna shorter, terminal antennomeres c. $2.55 \mathrm{x}$ as long as wide (N. Northern Territory)

P. rufopiceus Baehr, 1993

\section{REMARKS}

Most Australian species of Pogonoglossus are known from eastern Australia, i.e. from Iron Range in North Queensland to central eastern New South Wales; only P. porosus (Sloane, 1904) occurs across the tropical belt from North Queensland to the Kimberleys in far northern Australia, and the cavicolous P. rufopiceus is known from near Katherine in the northern part of the Northern Territory. Therefore, the discovery of two new species in the Pilbara, south of the Great Sandy Desert, is surprising, and considerably enlarges the range of the genus in Australia. The occurrence is surprising, because the genus Pogonoglossus certainly is an Oriental faunal element, species of which immigrated into Australia from the north, most probably from New Guinea via Cape York Peninsula. This immigration occurred rather recently, after the contact of Australia with the South Asian insular belt, and the immigration seems to continue, because one species, $P$. parvus Darlington, 1968, that was originally described from New Guinea, occurs in the Iron Range in mid Cape York Peninsula. This is an area well known for a number of species being conspecific with species occurring in New Guinea and the Oriental Region, or being still very closely related to such species. Thus, they seem to represent rather recent immigrants to Australia. Occurrence of such northern, 'Torresian' faunal elements in Western Australia south of Great Sandy Desert is surprising and very uncommon, and thus, the two new species are of major importance for biogeographic questions.

Those species of Physocrotaphini of which any knowledge about their habits is available, usually occur in open to closed forests, and probably they live under bark of trees and logs or in other crevices. Only a single species so far is known to have been found in a cave, the northern Australian P. rufopiceus Baehr, but outside of Australia no cavicolous or subterranean species of Physocrotaphini are known. Therefore the detection of two small eyed, depigmented, true humicolous species is important and enlightens our restricted knowledge about the habits of this carabid group.

This discovery of two soil inhabiting species also demonstrates our restricted knowledge not only of the fauna of north-western Australia, but particularly of the Australian cave and subterranean fauna in general. Application of the sampling method as used during the mentioned survey even more systematically and in other parts of Australia might considerably enlarge the number of such subterranean species, and thus might noticeably change our knowledge about the composition of the Australian carabid fauna in a same way as it happened by the discovery of the rich beetle fauna living in wells and generally in subterranean waters.

It should be mentioned that during the same survey also some depigmented, soil inhabiting Zuphiini and Anillina (Bembidiini) were found which presently are under examination.

\section{ACKNOWLEDGEMENTS}

I am indebted to Nadine Guthrie, Brian Hanich, and Nikolai Tatarnic (Perth) for the loan of the specimens, and to Dean Main (Perth) for additional information about sampling methods.

\section{REFERENCES}

Baehr, M. (1988). Revision of the Australian species of the genus Pogonoglossus Chaudoir (Insecta: Coleoptera: Carabidae: Helluodinae). Invertebrate Taxonomy 2: 961-972.

Baehr, M. (1993). A new species of Pogonoglossus Chaudoir from Australia (Insecta, Coleoptera, Carabidae, Helluodinae). Spixiana 16: 141-144.

Baehr, M. (1995). A peculiar new species of the genus Pogonoglossus Chaudoir from New Guinea (Insecta, Coleoptera, Carabidae, Helluodinae). Spixiana 18: 255-258.

Baehr, M. (2005). Two new species of the genus Pogonoglossus Chaudoir from New Guinea (Coleoptera, Carabidae, Physocrotaphinae). Bulletin de l'Institute Royale des Sciences Naturelles de Belgique 75: 5-12.

Baehr, M. (2008). A new species of the genus Pogonoglossus Chaudoir from Australia (Carabidae, Physocrotaphinae). Coleoptera 11 (2007): 105-111.

Darlington, P. J. Jr. (1968). The carabid beetles of New Guinea. Part III. Harpalinae continued. Perigonini to Pseudomorphini. Bulletin of the Museum of Comparative Zoology 139: 1-253.

Halse, S. A. and G. B. Pearson (2014). Troglofauna in the vadose zone: comparison of scraping and trapping results and sampling adequacy. Subterranean Biology 13: 17-34.

Lorenz, W. (2005). Systematic list of extant ground beetles of the world (Insecta Coleoptera "Geadephaga": Trachpachidae and Carabidae incl. Paussinae, Cicindelinae. Rhysodidae). 2nd edition. Printed by the author, Tutzing. $530 \mathrm{pp}$.

Moore, B. P. (1998). The enigmatic tribe Physocrotaphini Chaudoir (Helluodini auct.) (Coleoptera: Carabidae). In: Ball, G.E., Casale, A. and Vigna Taglianti, A. (eds), Phylogeny and classification of Caraboidea. Atti di Museo Regionale di Science Naturale de Torino 1998: 369-380.

MANUSCRIPT RECEIVED 5 JUNE 2014; ACCEPTED 13 NOVEMBER 2014. 